\title{
Study on thermal shock irradiation resistance of CoCrFeMnNi high entropy alloy by high intensity pulsed ion beam
}

\author{
Lisong Zhang ${ }^{\mathrm{a}}$, Xiaonan Zhang ${ }^{\mathrm{b}}$, Na $\mathrm{Li}^{\mathrm{a}}$, Xianxiu Mei ${ }^{\mathrm{a}} *$, Xiaona $\mathrm{Li}^{\mathrm{a}}$, Younian Wang ${ }^{\mathrm{a}}$, \\ Xingzhong Cao ${ }^{c}$, Sergey K. Pavlov ${ }^{d}$, Gennady E. Remnev ${ }^{\mathrm{d}}$, Vladimir V. Uglov ${ }^{\mathrm{e}}$, Eryang Lu ${ }^{\mathrm{f}}$ \\ ${ }^{a}$ Key Laboratory of Materials Modification by Laser, Ion and Electron Beams, Ministry of Education, Dalian University of Technology, Dalian 116024, China \\ ${ }^{\mathrm{b}}$ School of Science, Dalian Jiaotong University, Dalian 116028, China \\ ' Institute of High Energy Physics, Chinese Academy of Sciences, Beijing 100049, China \\ d National Research Tomsk Polytechnic University, Tomsk 634028, Russian Federation \\ ${ }^{\mathrm{e}}$ Belarusian State University, Minsk 220030, Belarus \\ ${ }^{\mathrm{f}}$ Department of Physics and Helsinki Institute of Physics, University of Helsinki, P.O. Box 43, FI-O O O14, Helsinki, Finland
}

a r t i 1 e in fo

Article history:

Received 31 August 2021

Revised 10 November 2021

Accepted 15 November 2021

Available online $\mathrm{xxx}$

\section{Keywords:}

High entropy alloys

High intensity pulsed ion beam (HIPIB)

Irradiation damage

Irradiation stability

Thermal stability

\begin{abstract}
$\mathrm{abstract}$
In recent years, high entropy alloys (HEAs) have attracted significant attention due to their excellent physical, chemical, mechanical properties, and good irradiation resistance, thus are considered as potential candidates for fission and fusion structural applications. CoCrFeMnNi HEA was irradiated by high intensity pulsed ion beam (HIPIB) to investigate the effects of thermal shock irradiation on its microstructure, surface morphology and mechanical properties. It was found that CoCrFeMnNi HEA maintained the face-centered cubic single-phase structure after HIPIB irradiation. The ion beam effect of irradiation produced numerous defects such as vacancies and stacking faults within the range of carbon ions. While the thermal effect reduced vacancy concentration beyond the ion range by promoting the recombination of vacancies with interstitials, and decreased the nano-hardness of CoCrFeMnNi HEA. The thermal effect and shock wave effect promoted the migration of vacancies and formed defects such as stacking faults etc. far beyond the ion range in CoCrFeMnNi HEA. Because of the very compositional complexity, the high-level chemical disorder and local lattice distortion of CoCrFeMnNi HEA, the lattice parameter was almost unchanged after HIPIB irradiation. Even if the temperature reached the melting point of CoCrFeMnNi HEA, there was no crack on the surface after surface remelting and rapid cooling. CoCrFeMnNi HEA showed good thermal stability and thermal shock irradiation resistance.
\end{abstract}

\section{Introduction}

The development of advanced fission and fusion reactors depends largely on the stability performance of structural materials in extreme environments such as high temperature, high stress and strong irradiation damage [1,2]. Compared to conventional alloys containing only one major element, high entropy alloys (HEAs) [3], an emerging multi-principal element solid solution alloy, exhibit excellent mechanical properties [4,5] and high temperature stability [6,7] due to their complicated random arrangement of alloying elements and the characteristic of local chemical environment at the atomic level. Therefore, HEAs, regarded as a new candidate structural material in nuclear reactors, have become a research hotspot [8,9]. CoCrFeMnNi HEA is one of the earliest studied HEA systems [10], and can form face-centered cubic (FCC) single-phase

\footnotetext{
* Corresponding author at: Dalian City, Liaoning Province, 116024, China E-mail address: xxmei@dlut.edu.cn (X. Mei).
}

solid solution structure well. In addition, it is also one of the earliest HEA systems which used in irradiation research [11,12], and shows good irradiation resistance, such as promoting defect recombination [12], inhibiting irradiation-induced swelling [11] and segregation [13], defect accumulation [14] and He bubble growth [15], etc.

In the fusion device, there are not only plasma and neutron irradiation, but also strong thermal radiation up to $800^{\circ} \mathrm{C}$ [16]. Among the conditions that affect irradiation damage build-up (e.g., particle energy, dose, and dose rate), irradiation temperature can influence defect production, migration, and evolution significantly. Compared with conventional alloys, HEAs can still maintain high structural stability [17,18] and low irradiation swelling rate [19], while reducing irradiation-induced segregation and defect accumulation [17], and inhibiting the nucleation and growth of He bubbles $[20,21]$ during high temperature irradiation. However, the ambient temperature of the reactor wall material is not constant, and the material often experiences transient high thermal load shocks due 
to unstable rupture of the plasma [22]. Thus, it is important to study the irradiation damage evolution of HEAs under high thermal load shocks for their potential application in nuclear reactors.

High Intensity Pulsed Ion Beam (HIPIB) combines ion beam ef-

fect and thermal effect with achieving high energy density deposition $\left(10^{6}-10^{11} \mathrm{~W} / \mathrm{cm}^{2}\right)$ on the material surface instantly $(\leq 1$ $\mu \mathrm{s})$, causing rapid heating $\left(10^{8}-10^{11} \mathrm{~K} / \mathrm{s}\right)$ and cooling $\left(10^{8}-10^{9} \mathrm{~K} / \mathrm{s}\right)$ $[23,24]$. The strong thermal effect can lead to melting, evaporation and ablation of the material surface, and also the formation of non-equilibrium phases $[25,26]$. In addition, the rapid temperature variation generates shock wave and high thermal stress, resulting in severe irradiation damage (e.g., cracking, spalling, etc. [27,28]) with influence depth of tens of $\mu \mathrm{m}$ [29]. Therefore, HIPIB is suitable for simulating thermal irradiation in a fusion device, and can even simulate transient thermal shock when unstable plasma ruptures [30,31]. CoCrFeMnNi HEA was irradiated by HIPIB to study its microstructure, surface morphology and mechanical property response under thermal shock irradiation. It provided the theoretical data reference for the selection and research of structural materials in nuclear devices.

\section{Experimental}

The CoCrFeMnNi HEA was prepared by vacuum arc melting with constituent elemental purity higher than 99.95 wt.\%. To achieve a homogeneous distribution of elements, each alloy was remelted and flipped five times with electromagnetic stirring. The details of the melting process can be found in Ref. $[32,33]$. Before irradiation, the CoCrFeMnNi HEA with the size of $8 \mathrm{~mm} \times 5 \mathrm{~mm} \times 2 \mathrm{~mm}$ was polished using silicon carbide paper up to 2000 grit followed by a final polishing step using $1 \mu \mathrm{m}$ diamond polishing paste.

The experiment of HIPIB irradiation was performed on the Temp-4M high intensity pulsed ion beam device at Tomsk Polytechnic University in Russia [34,35]. The accelerator has a doublepulse mode, and the ion beam generates from its magnetic insulating diode, whose anode and cathode material are graphite and stainless steel. The ion beam consists of $85 \% \mathrm{C}^{\mathrm{n}_{+}}\left(\right.$mostly $\left.\mathrm{C}^{+}\right)$and $15 \% \mathrm{H}^{+}$. The acceleration voltage, pulse width and pulse interval are $220 \mathrm{kV}, \sim 90 \mathrm{~ns}$ and $10 \mathrm{~s}$, respectively. The experimental parameters were divided into two groups. The pulse number of the first group were $3,10,100$ and 300 with a same energy density of $0.3 \mathrm{~J} / \mathrm{cm}^{2}$; the second group was 3 pulses and changed the energy density from 0.3 to $0.5,1.2$ and $2.0 \mathrm{~J} / \mathrm{cm}^{2}$ respectively.

The Stopping and Range of Ions in Matters (SRIM) program [36] was used to simulate the distributions of displacements per atom (dpa) and ions concentration in HIPIB irradiated CoCrFeMnNi HEA (the ion beam effect). The finite element method (FEM)

[37] was used to simulate the time and space evolutions of temperature and thermal stress in HIPIB irradiated CoCrFeMnNi HEA (thermal effect and shock wave effect).

Scanning electron microscope (SEM) was used to test the surface morphology of samples. The phase structure of un-irradiated and irradiated samples was studied by X-ray diffraction (XRD) with $\mathrm{Cu} \mathrm{K} \alpha$ radiation. The changes on microstructure were studied by transmission electron microscope (TEM). The samples for TEM were manufactured by focused ion beam (FIB) method. The depth distribution of defects induced by the irradiation in CoCrFeMnNi HEA was analyzed by the Doppler broadening spectroscopy (DBS) of slow positron beam. The positron annihilation measurements were performed at the Positron Research Platform of the Institute of High Energy Physics, Beijing, China, using a ${ }^{22} \mathrm{Na}$ positron source and a high-purity germanium detector to detect the $\gamma$ photons generated by positron annihilation [38]. The hardness variations of the surface were measured by a micro-nanoindenter with an in- dentation depth of $2 \mu \mathrm{m}$ and a loading time and unloading time of $40 \mathrm{~s}$.

\section{Results and discussion}

\subsection{The simulation of CoCrFeMnNi HEA irradiated by HIPIB}

The distributions of dpa and ions concentrations in HIPIB irradiated CoCrFeMnNi HEA (the ion beam effect) were simulated by SRIM in full-cascade mode [39]. The displacement energy was set as $40 \mathrm{eV}$ for all target elements [19,40,41]. Fig. 1 shows the distributions of dpa and the concentrations of implanted carbon and hydrogen as a function of depth in the CoCrFeMnNi HEA with the irradiation condition of $0.3 \mathrm{~J} / \mathrm{cm}^{2}, 300$ pulses and $2.0 \mathrm{~J} / \mathrm{cm}^{2}, 3$ pulses, and the inset is an enlargement of the dpa curve. The dpa curves are bimodal, corresponding to the dpa produced by carbon and hydrogen respectively. The dpa produced by carbon was concentrated at $0-400 \mathrm{~nm}$ and much larger than the dpa produced by hydrogen, which indicated that the displacement damage was mainly produced by the cascade collisions of carbon. On the one hand, the amount of carbon in the ion beam was much larger than that of hydrogen; on the other hand, the mass of hydrogen was small, the range was long, and the nuclear energy loss of hydrogen was only $0.6 \%$ of the total energy. Therefore, hydrogen produced less displacement damage in the CoCrFeMnNi HEA. In addition, the dpa and implanted atoms concentrations were larger at the irradiation of $0.3 \mathrm{~J} / \mathrm{cm}^{2}, 300$ pulses, which implied more vacancies induced by irradiation and a stronger ion beam effect.

The time and space evolutions of temperature and thermal stress in HIPIB irradiated CoCrFeMnNi HEA (thermal effect and shock wave effect) were simulated by FEM. According to the law of conservation of energy, the temperature field $T(x, t)$ can be expressed as:

$\rho(T) C(T) \frac{\partial T(x, t)}{\partial t}=\lambda(T) \frac{\partial^{2} T(x, t)}{\partial x^{2}}+P-L \delta\left(T(x, t)-T_{m}\right)$,

$P(x, t)=k \cdot d(x) \cdot f(t)$

where $\rho(T)$ is the density, $C(T)$ is the specific heat capacity, $\lambda(T)$ is the thermal conductivity, and $L$ is the latent heat of fusion. The melting point $\left(T_{m}\right)$ of CoCrFeMnNi HEA is $1607 \mathrm{~K}$ [42]. The initial condition is $T(x, 0)=298 \mathrm{~K}$. As the irradiation was performed in a vacuum chamber, the boundary condition is set to adiabatic condition. $P$ is the source term, and $k$ is the energy density, $d(x)$ is the distribution function of ion beam energy with depth, which was calculated by SRIM. The current density evolution function with time is given by $f(t)$, and its evolution of the TEMP-4M device was taken from the paper [43]. Both $f(t)$ and $d(x)$ are normalized functions. The density, coefficient of thermal expansion, specific heat capacity, thermal conductivity, Young's modulus and Poisson's ratio of $\mathrm{CoCrFeMnNi} \mathrm{HEA} \mathrm{with} \mathrm{temperature} \mathrm{were} \mathrm{taken} \mathrm{from} \mathrm{the} \mathrm{papers}$ [44] and [45]. The latent heat of fusion and the thermal parameters for liquid state with temperature were the average values of $\mathrm{Co}, \mathrm{Cr}$, $\mathrm{Fe}, \mathrm{Mn}$ and Ni (taken from the Material Property Database of JAHM Software, Inc.). Considering the time complexity, space complexity and computational accuracy of the simulation, the minimum time step and space unit were set to be $10 \mathrm{~ns}$ and $10 \mathrm{~nm}$, respectively.

The temperature evolutions with time and space of $\mathrm{CoCrFeMnNi}$ HEA irradiated by different energy densities are shown in Fig. 2. The irradiation deposited a large amount of energy on the surface within $0.14 \mu \mathrm{s}$, which made the surface temperature rise rapidly to the highest temperature $\mathrm{T}_{\max }$ with a maximum heating rate of $10^{10} \mathrm{~K} / \mathrm{s}$ magnitude. At the same time, the heat transferred rapidly from the surface to the interior through heat conduction, with a maximum cooling rate of $10^{9}-10^{10} \mathrm{~K} / \mathrm{s}$ magnitude. Due to the rapid energy deposition, the maximum heating rate was larger than the 

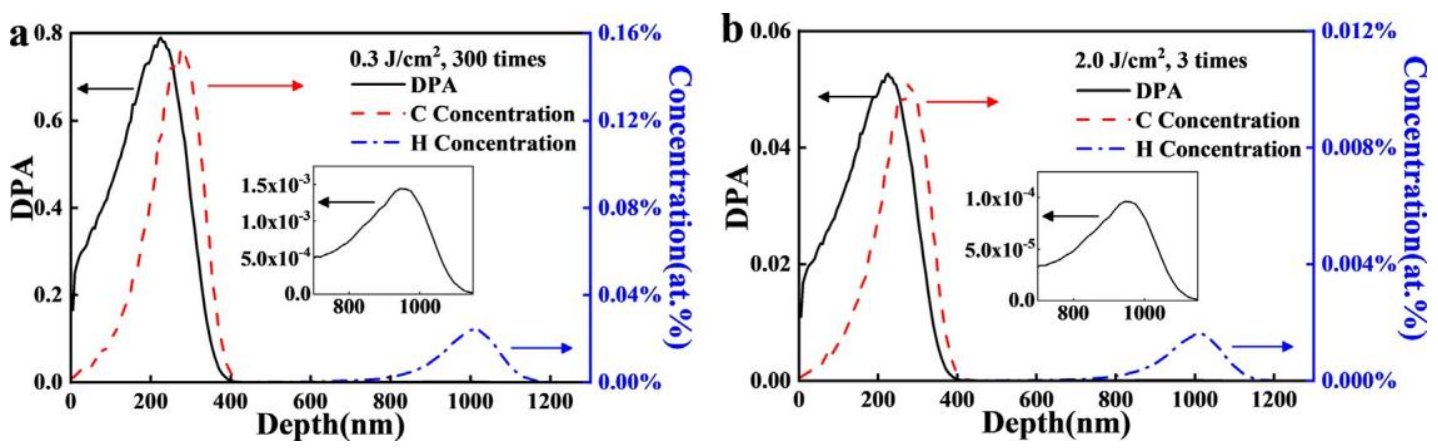

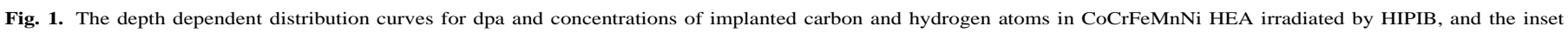
is an enlargement of the dpa curve: (a) $0.3 \mathrm{~J} / \mathrm{cm}^{2}, 300$ pulses and (b) $2.0 \mathrm{~J} / \mathrm{cm}^{2}, 3$ pulses.
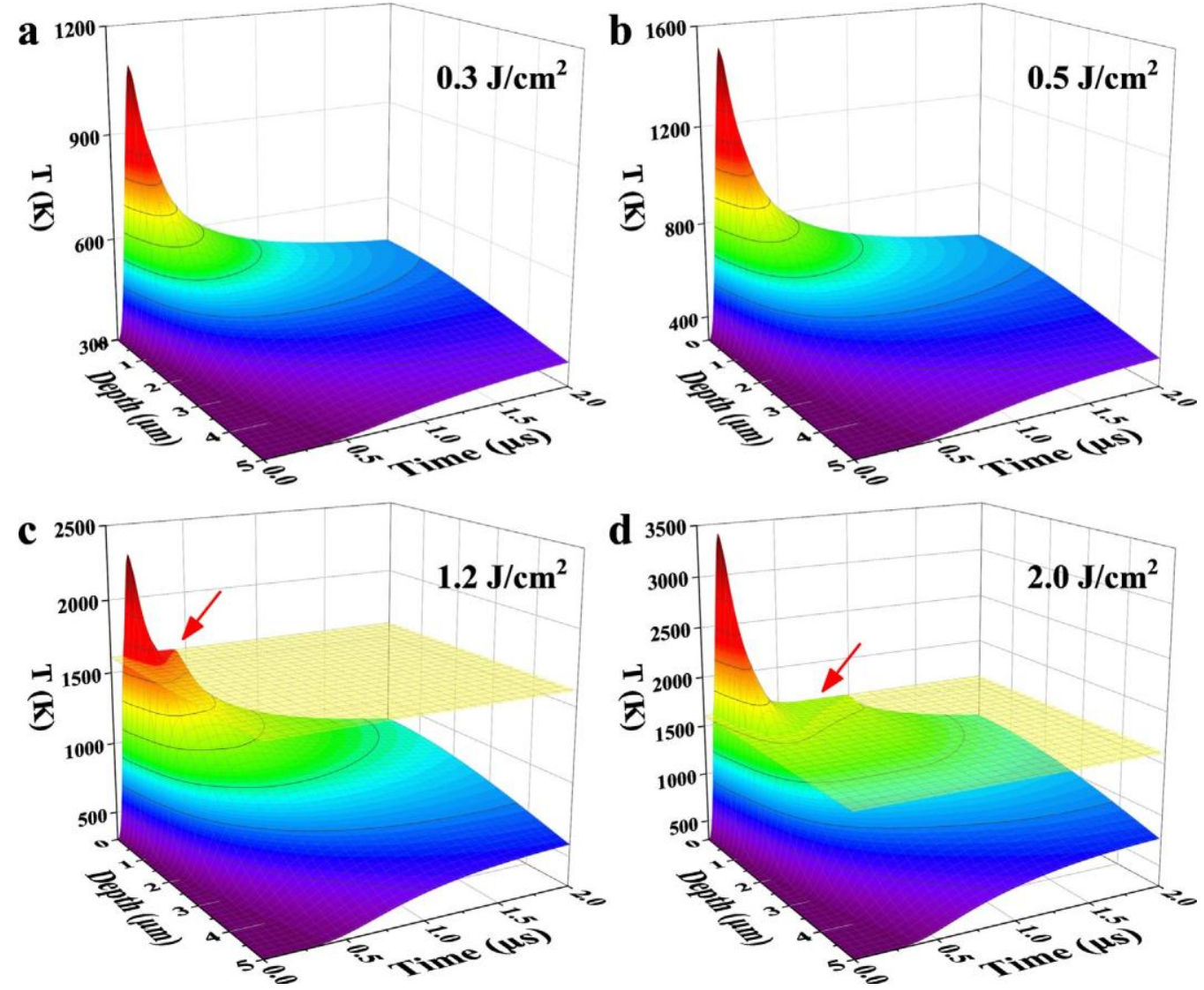

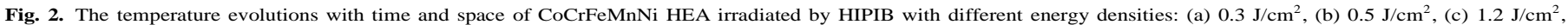

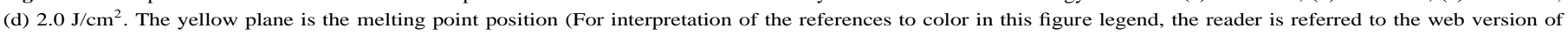
this article).

maximum cooling rate at the same energy density. It can be seen from the Fig. 2 that the maximum temperature, melting depth and time, high temperature region range, maximum heating and cooling rate all increased with the energy density, and the calculated results were summarized in Table 1 . At the energy densities of $1.2 \mathrm{~J} / \mathrm{cm}^{2}$ and $2.0 \mathrm{~J} / \mathrm{cm}^{2}$, the maximum temperature of $\mathrm{CoCrFeMnNi}$ HEA exceeded the melting point (the melting point position was marked by a plane in Fig. $2 \mathrm{c}$ and $2 \mathrm{~d}$ ). And the melting depths were $\sim 0.8 \mu \mathrm{m}$ and $\sim 1.5 \mu \mathrm{m}$, the melting time were $\sim 0.3 \mu \mathrm{s}$ and $\sim 0.9 \mu \mathrm{s}$, respectively. As shown by the red arrows, the solidification process of CoCrFeMnNi HEA lasts about a few hundred nanoseconds due to the latent heat of solidification (equal to the latent heat of fusion).

Fig. 3 shows the evolutions of thermal stress with time and space for CoCrFeMnNi HEA irradiated with different energy densities, where the positive stress is compressive stress along the depth direction and the negative stress is tensile stress. Because of the rapid heating and cooling, the irradiation produced strong shock waves within the CoCrFeMnNi HEA, and the thermal stress increased rapidly to the maximum compressive stress within 0.2 $\mu$ s. Not only compressive stresses, as time increases, but also little tensile stresses generated due to the rapid cooling of the CoCrFeMnNi HEA surface layer. With the increase of energy density, the increase of heating and cooling rate led to the increase of maximum compressive stress $\sigma_{\mathrm{c} \text {, max }}$ and maximum tensile stress $\sigma_{\mathrm{t}, \max }$, as shown in Table 2 .

We refer to the region where the temperature exceeds the recrystallization temperature (about $873 \mathrm{~K}[46,47]$ ) and the stress exceeds the yield strength (about $200 \mathrm{MPa}[48]$ ) as the high temperature region and the high stress region, respectively. The influence ranges of the high temperature region and high stress region 
Table 1

Calculation results of temperature field of CoCrFeMnNi HEA irradiated by HIPIB

\begin{tabular}{|c|c|c|c|c|c|c|c|}
\hline \multirow{2}{*}{$\begin{array}{l}\text { energy density, } \\
\mathrm{J} / \mathrm{cm}^{-}\end{array}$} & \multirow{2}{*}{$1_{\max }, \mathbf{K}$} & \multicolumn{2}{|c|}{ melting region } & \multirow{2}{*}{$\begin{array}{l}\text { maximum heating } \\
\text {-rate, } 1 U^{-\cdots} \mathrm{K} / \mathrm{s}\end{array}$} & \multirow{2}{*}{$\begin{array}{l}\text { maximum cooling } \\
\text { rate, } 1 U^{\cdots} \mathrm{K} / \mathrm{s}\end{array}$} & \multicolumn{2}{|c|}{ high temperature region } \\
\hline & & depth, $\mu \mathrm{m}$ & time, $\mu \mathrm{s}$ & & & depth, $\mu \mathrm{m}$ & time, $\mu \mathrm{s}$ \\
\hline 0.3 & 1089 & & & 0.9 & 0.3 & $0-0.5$ & $0.1-0.2$ \\
\hline 0.5 & 1509 & & & 1.4 & 0.5 & $0-1.0$ & $0.1-0.4$ \\
\hline 1.2 & 2298 & $0-0.8$ & $0.1-0.4$ & 2.8 & 1.0 & $0-2.5$ & $0.1-1.9$ \\
\hline 2.0 & 3408 & $0-1.5$ & $0.1-1.0$ & 3.8 & 1.8 & $0-4.2$ & $0.1-5.2$ \\
\hline
\end{tabular}
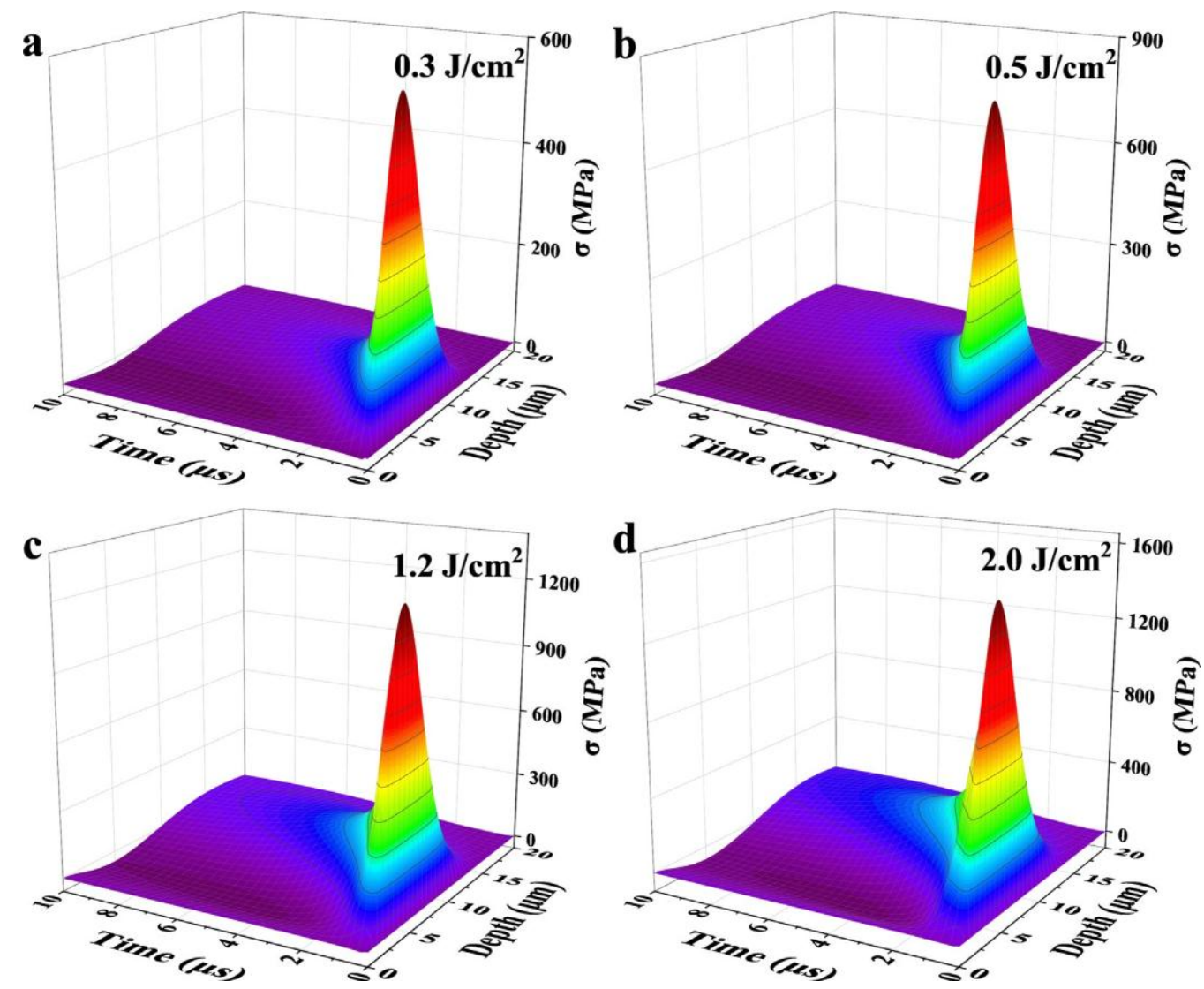

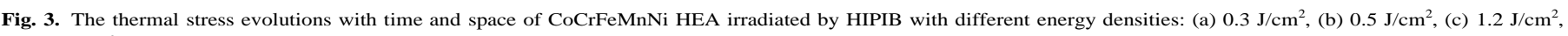
(d) $2.0 \mathrm{~J} / \mathrm{cm}^{2}$.

Table 2

Calculation results of stress field of CoCrFeMnNi HEA irradiated by HIPIB.

\begin{tabular}{lllll}
\hline \multirow{2}{*}{$\begin{array}{l}\text { energy density } \\
\mathrm{J} / \mathrm{cm}^{2}\end{array}$} & $\sigma_{\mathrm{c}, \max }, \mathrm{MPa}$ & $\sigma_{\mathrm{t}, \max ,} \mathrm{MPa}$ & \multicolumn{2}{l}{ high stress region } \\
\cline { 4 - 5 } & & & depth, $\boldsymbol{\mu m}$ & time, $\boldsymbol{\mu s}$ \\
\hline 0.3 & 583 & 13 & $1.5-8.1$ & $0.1-1.1$ \\
0.5 & 848 & 22 & $1.3-9.4$ & $0.1-1.7$ \\
1.2 & 1289 & 56 & $1.2-12.6$ & $0.1-3.6$ \\
2.0 & 1533 & 91 & $1.2-15.1$ & $0.1-5.2$ \\
\hline
\end{tabular}

can be clearly seen by the method of plotting the temperature and thermal stress contour maps, and the obtained ranges are summarized in Table 1 and Table 2, respectively. With the increase of energy density, both thermal effect and shock wave effect gradually enhanced and their influence range also increased. Fig. 4 shows the temperature and thermal stress contour maps of the CoCrFeMnNi HEA irradiated with the energy density of $2.0 \mathrm{~J} / \mathrm{cm}^{2}$. The ranges of the main influence regions of thermal effect and shock wave effect at $2.0 \mathrm{~J} / \mathrm{cm}^{2}$ irradiation were about $0-4.2 \mu \mathrm{m}$ and $1.2-15.1 \mu \mathrm{m}$, respectively, which were both larger than the influence range of ion beam effect $(0-0.4 \mu \mathrm{m})$. The surface of $\mathrm{CoCrFeMnNi} \mathrm{HEA}$ is free and the local constraint increases with depth, so the depth range of high stress concentration region was from 1.2 to $15.1 \mu \mathrm{m}$ instead of the most surface. The order of effects according to the depth of influence was: shock wave effect $>$ thermal effect $>$ ion beam effect.

\subsection{The effects of HIPIB irradiation on microstructure, surface morphology and mechanical property of CoCrFeMnNi HEA}

Fig. 5a shows the grazing incidence X-ray diffraction (GIXRD) patterns of CoCrFeMnNi HEA before and after HIPIB irradiation, with an incidence angle of one degree and a measurement range of about 0-400 nm depth. The CoCrFeMnNi HEA still maintained its FCC single-phase structure after irradiation. Due to the large grain size (about submillimeter), XRD measurements with different angles of sample placement resulted in diffraction enhancement on different grain planes, such as (200), (220) and (311) diffraction peaks. Fig. 5b shows the enlarged patterns of (111) plane diffraction peak in Fig. 5a. There was almost no shift of the diffraction peaks in CoCrFeMnNi HEA after the irradiation of $0.3 \mathrm{~J} / \mathrm{cm}^{2}$, different pulses and $0.5 \mathrm{~J} / \mathrm{cm}^{2}, 3$ pulses, while significant shift was observed under similar conditions in tungsten [49]. Severe lattice dis- 

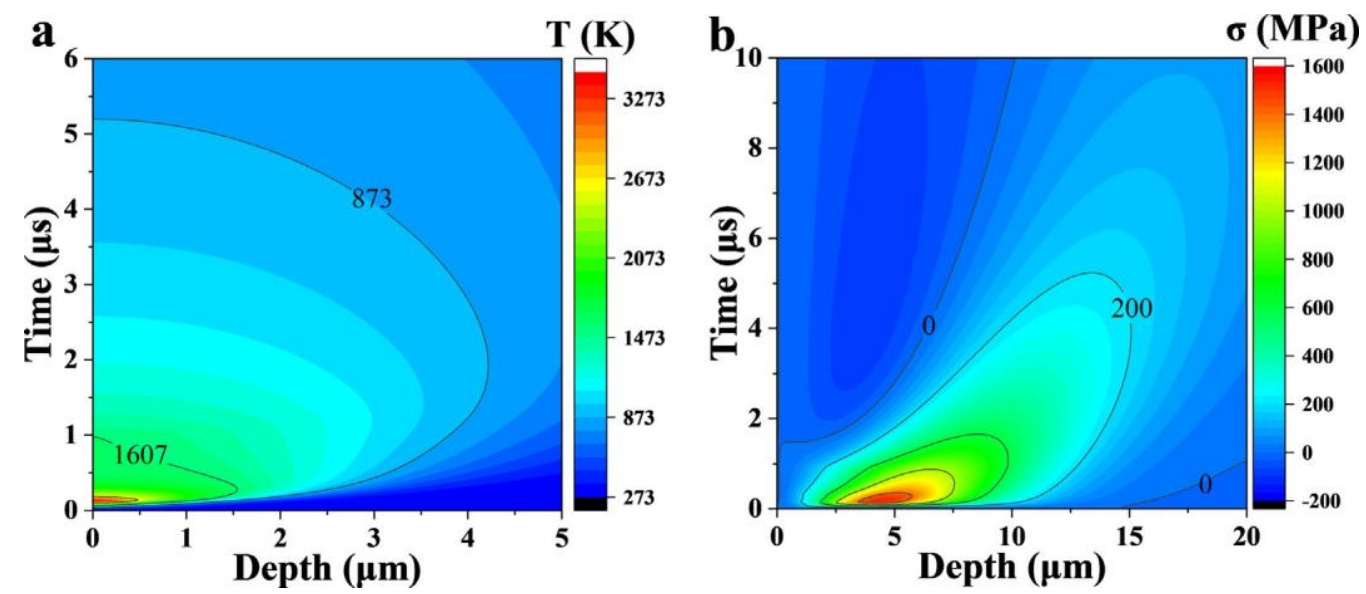

Fig. 4. (a) The temperature contour map and (b) the thermal stress contour map of the CoCrFeMnNi HEA irradiated with the energy density of $2.0 \mathrm{~J} / \mathrm{cm}^{2}$.
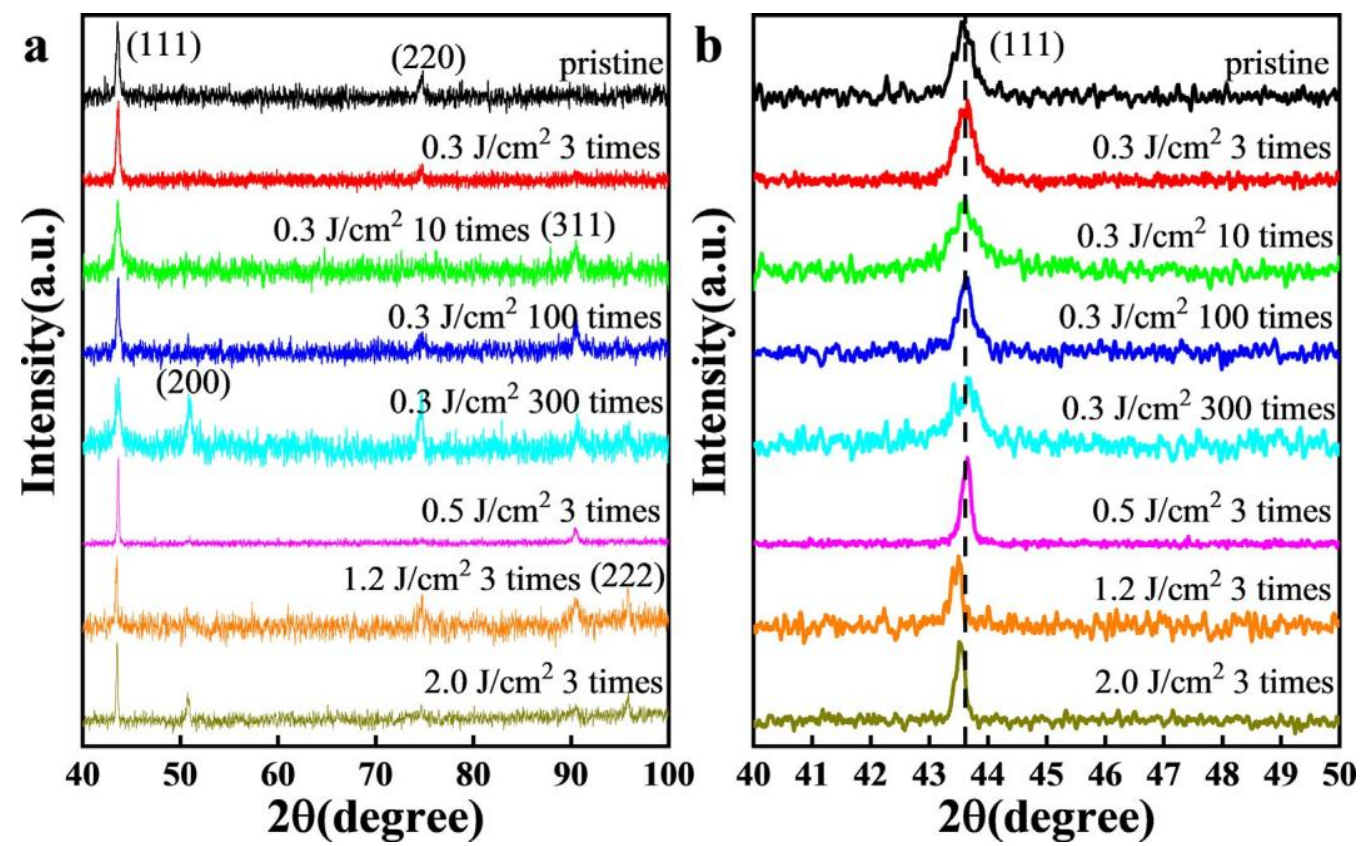

Fig. 5. (a) GIXRD patterns of CoCrFeMnNi HEA before and after HIPIIB irradiation; (b) the enlarged patterns of (111) plane diffraction peak in (a).

tortion in HEA leads to higher lattice strain energy [50], suppressing lattice strain generation and improving the structural stability. When the energy density increased to $1.2 \mathrm{~J} / \mathrm{cm}^{2}$ and $2.0 \mathrm{~J} / \mathrm{cm}^{2}$, the diffraction peaks moved towards the low angle region, which means a slight increase of the lattice parameter (from $0.3593 \mathrm{~nm}$ of pristine to $\sim 0.3601 \mathrm{~nm}$ of remelted HEA), owing to the tensile stress generated by surface layer remelting and rapid solidification.

Fig. 6a shows the XRD patterns of $\theta-2 \theta$ coupled scan of CoCrFeMnNi HEA before and after HIPIB irradiation, with a measure-

ment range of about $0-16 \mu \mathrm{m}$ depth. Fig. $6 \mathrm{~b}$ shows the enlarged patterns of (111) plane diffraction peak in Fig. 6a. As the pulses ( $\geq 100$ times) and energy density $\left(\geq 0.5 \mathrm{~J} / \mathrm{cm}^{2}\right)$ increased, the diffraction peaks moved towards the high-angle region, indicating a slight reduction of lattice parameter and the presence of compressive stress. According to the simulation results of stress field in Fig. 3, the compressive stress produced by the shock wave effect was greater than the yield strength in the depth range of 1.2$15.1 \mu \mathrm{m}$, resulting in the compression of lattice within the CoCrFeMnNi HEA.

Fig. $7 \mathrm{a}$ and $7 \mathrm{~b}$ show the TEM cross-sectional images of $\mathrm{CoCr}-$ FeMnNi HEA under HIPIB irradiation of $0.3 \mathrm{~J} / \mathrm{cm}^{2}, 300$ pulses and
$2.0 \mathrm{~J} / \mathrm{cm}^{2}, 3$ pulses, respectively. The temperature of CoCrFeMnNi HEA did not reach the melting point at the irradiation of $0.3 \mathrm{~J} / \mathrm{cm}^{2}$, 300 pulses, and the irradiation-induced defects accumulated in the cascade collision region (up to $400 \mathrm{~nm}$ depth), thus producing an obvious defect layer. For the irradiation of $2.0 \mathrm{~J} / \mathrm{cm}^{2}, 3$ pulses, its dpa was much less than that of $0.3 \mathrm{~J} / \mathrm{cm}^{2}, 300$ pulses, and the remelting resulted in the reduction of irradiation-induced defects, so Fig. $7 \mathrm{~b}$ shows less irradiation defects. From the selected area electron diffraction (SAED) patterns in Fig. $7 \mathrm{c}$ and $7 \mathrm{~d}$, it is clear that the CoCrFeMnNi HEA still maintained a good FCC single-phase structure after the HIPIB irradiation, which agrees with the XRD result of Fig. 5.

The HRTEM images of CoCrFeMnNi HEA at different depths after the HIPIB irradiation of $0.3 \mathrm{~J} / \mathrm{cm}^{2}, 300$ pulses and $2.0 \mathrm{~J} / \mathrm{cm}^{2}$, 3 pulses were given in Fig. $8 a_{1}-a_{4}$ and $8 b_{1}-b_{4}$, respectively. The irradiation-induced stacking faults (SFs) were observed in $\mathrm{CoCr}$ FeMnNi HEA within the depth range of $0-2 \mu \mathrm{m}$ for both irradiation of low energy density, multiple pulses $\left(0.3 \mathrm{~J} / \mathrm{cm}^{2}, 300\right.$ pulses $)$ and high energy density, few pulses $\left(2.0 \mathrm{~J} / \mathrm{cm}^{2}, 3\right.$ pulses $)$, as indicated by the red arrows. HEA has lower stacking fault energy (SFE) than conventional alloys due to severe lattice distortion [50], and 

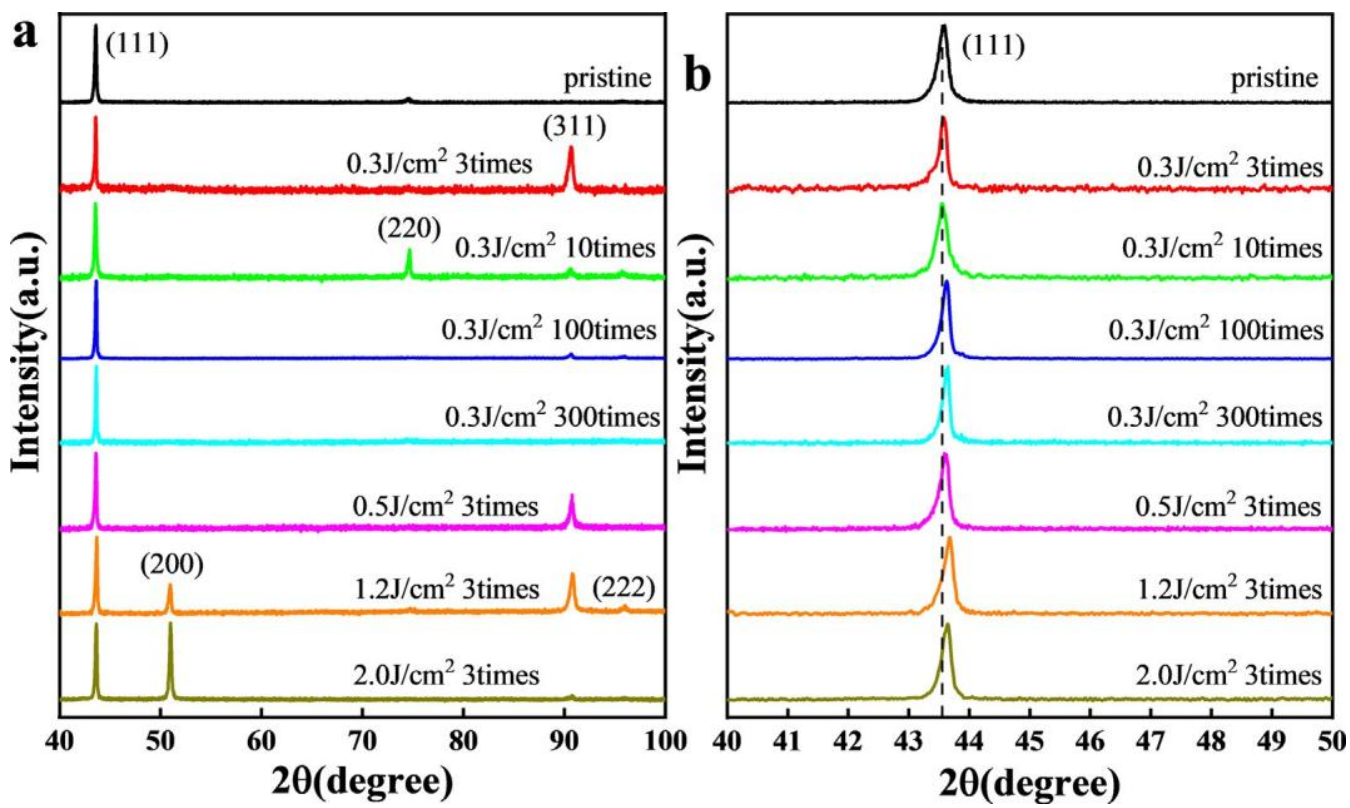

Fig. 6. (a) $\theta-2 \theta$ XRD patterns of CoCrFeMnNi HEA before and after HIPIIB irradiation; (b) the enlarged patterns of (111) plane diffraction peak in (a).

the SFE of CoCrFeMnNi HEA is only $\sim 20 \mathrm{~mJ} / \mathrm{m}^{2}$ [51]. The low SFE means that SFs are more likely to form in HEA, and irradiationinduced SFs have also been observed within ion range in other studies about HEA [52,53]. The ion collisions, high temperature and stress all promoted the migration of vacancies to form SFs, where both the influence depths of temperature and stress were more than $2 \mu \mathrm{m}$ (Fig. 2 and 3), hence the SFs also generated at the depth beyond the ion range. The angle between SFs can be found in some HRTEM images as $\sim 70.5^{\circ}$, which is consistent with the angle between (111) crystal planes in the SAED spectrums (Fig. 7c and 7d). This indicated that SFs were located in (111) crystal planes. The (111) crystal planes are the close-packed planes of the FCC structure, on which defects such as dislocation rings or SFs are more likely to form.

The positrons annihilate with electrons at defects, and emit $\gamma$ photons with the energy of $511 \mathrm{keV}$. Due to the Doppler effect from the momentum of annihilated electron, the energy shift widens the energy of $\gamma$ photons. The $\mathrm{S}$ parameter is defined as the ratio of the counts in central low electron-momentum area $(510.2-511.8 \mathrm{keV})$ in the DBS to the total counts $(499.5-522.5 \mathrm{keV})$, characterizing the annihilation of positrons with the valence electrons, and increases with the volume fraction of vacancy-type defects. The $\mathrm{W}$ parameter is defined as the ratio of the counts in two flanks high electron-momentum regions (513.6-516.9 keV and $505.1-508.4 \mathrm{keV}$ ) to the total counts, characterizing the annihilation of positrons with the core electrons, and is sensitive to the chemical nature at the annihilation site. The accelerated energy range of the positrons injecting into CoCeFeNiMn HEA was 0.5$25 \mathrm{keV}$, and the corresponding injected depth $R$ was given by the empirical formula[54]:

$R=\frac{40}{\rho} E^{1.6}$,

where $\rho$ is the density of $\mathrm{CoCrFeMnNi}$ HEA with the value of $8.059 \mathrm{~g} / \mathrm{cm}^{3} ; E$ is the energy of injected positron.

Fig. 9a shows the distributions of $\mathrm{S}$ parameter with depth for CoCrFeMnNi HEA before and after the irradiation of $0.3 \mathrm{~J} / \mathrm{cm}^{2}$, different pulses. Positron annihilation measurements are sensitive to the processing history of the sample (e.g., annealing and polishing). Due to the damage of the surface by mechanical polishing, the $\mathrm{S}$ parameter of the pristine CoCrFeMnNi HEA showed a ten- dency to first decrease, then increase and finally stabilize. The unannealed as-cast sample had higher vacancy concentration compared to the well annealed CoCrFeMnNi HEA (annealed at $1200{ }^{\circ} \mathrm{C}$ for $3 \mathrm{~h}$ followed by water-quenching). Due to the high configurational entropy, the equilibrium vacancy concentrations in HEA are substantially larger than those in pure metal and conventional alloy (such as $316 \mathrm{~L}$ steel) [55,56], and the pristine CoCrFeMnNi HEA has a high $\mathrm{S}$ parameter $\sim 0.475$. After the irradiation of $0.3 \mathrm{~J} / \mathrm{cm}^{2}$, 3 pulses, the S parameter did not change obviously in the cascade collision region $(0-400 \mathrm{~nm})$, while decreased slightly in the 400 $900 \mathrm{~nm}$ depth region. When the number of pulses increased to 100 and 300 , the vacancy-type defects increased significantly in the cascade collision region, while gradually decreased to the value below the un-irradiated CoCrFeMnNi HEA in the 400-900 nm depth region. The SRIM simulation shows that after the irradiation of $0.3 \mathrm{~J} / \mathrm{cm}^{2}, 300$ pulses, the ion beam effect produced a large number of vacancies in the cascade collision region (Fig. 1a), which is the main factor leading to the increase of S parameter. Meanwhile, SFs induced by the irradiation (Fig. 8) also contributed to the increase of S parameter. There are numerous vacancies in the pristine $\mathrm{CoCrFeMnNi} \mathrm{HEA}$, and the thermal effect can increase the mobility of vacancies and interstitials, thus promoting their recombination and reducing the $S$ parameter. In addition, due to the self-healing mechanism of HEA, the enhanced vacancy-interstitial spontaneous recombination radii also further increase the recombination rate of point defects during irradiation [17]. In the cascade collision region of CoCrFeMnNi HEA under the irradiation of $0.3 \mathrm{~J} / \mathrm{cm}^{2}, 100$ 300 pulses, the competition occurred among the ion beam effect, the generation of SFs and the thermal effect, and the ion beam effect played a major role, leading to the increase of $S$ parameter. At the depth of 400-900 $\mathrm{nm}$, the influence of ion beam effect gradually decreased, on the contrary, the thermal effect was dominant and its range of influence was far beyond the positron annihilation measurement range, leading to the reduced $S$ parameter. Fig. $9 b$ shows the distributions of $\mathrm{S}$ parameter with depth for $\mathrm{CoCrFeMnNi}$ HEA before and after the irradiation of different energy densities, 3 pulses. When the energy densities were $0.3-1.2 \mathrm{~J} / \mathrm{cm}^{2}$, the stronger thermal effect led to the decrease of $S$ parameter with the increasing of energy density, but the $\mathrm{S}$ parameter no longer decreased at $2.0 \mathrm{~J} / \mathrm{cm}^{2}$. According to the simulation of temperature field, the 

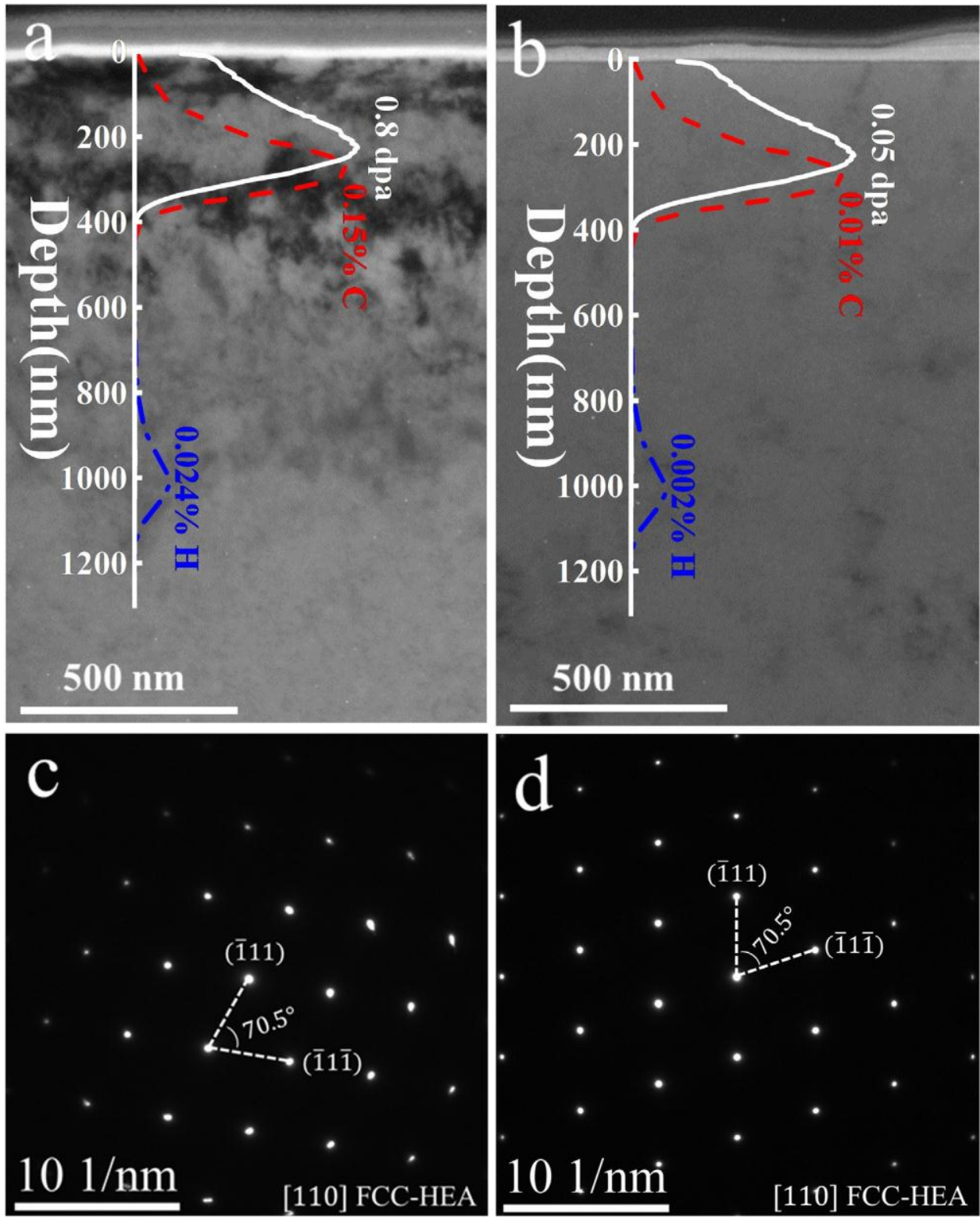

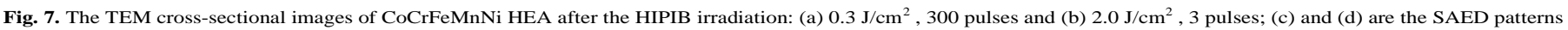
of (a) and (b) along [110] zone axis in the range of $0-400 \mathrm{~nm}$, respectively.

maximum temperature of CoCrFeMnNi HEA exceeded its melting point at $1.2 \mathrm{~J} / \mathrm{cm}^{2}$ and $2.0 \mathrm{~J} / \mathrm{cm}^{2}$, and the remelting made the vacancies and interstitials fully recombine. From Fig. 9a and 9b, the $S$ parameters of the irradiated samples were all larger than that of the well annealed sample, indicating that there were more defects in the irradiated samples. Because the irradiation of multiple pulses and low energy density had stronger ion beam effect (Fig. 1) and weaker thermal effect (Fig. 2) than the irradiation of high energy density with few pulses, the defects accumulated heavily in the cascade collision region, which is consistent with the results observed in the TEM images (Fig. 7).

Fig. 10 shows the S-W plots of CoCrFeMnNi HEA before and after HIPIB irradiation. The slope variation of the S-W curve reflects the change of defect types in the material $[53,57]$. The S-W curve of the well annealed and electrochemically polished $\mathrm{CoCrFeMnNi}$ HEA showed a straight line, while the mechanical polishing introduced additional damage on surface and the S-W curve of the ascast pristine sample exhibited both the surface state and the bulk state (Fig. 10a). The bulk state defect (slope I) of the pristine sam- ple was an inherent vacancy defect. Fig. 10b shows the S-W plot after the irradiation of $0.3 \mathrm{~J} / \mathrm{cm}^{2}$, different pulses. It is observed that there is a defect state (slope II) apart from the surface state and the bulk state for the pristine sample. As the number of pulses increased, the slope remained the same, but the S-W curve shifted to the lower right, which means that the number of pulses did not change the defect type but increased the concentration. When the energy density reached $0.5 \mathrm{~J} / \mathrm{cm}^{2}$ (Fig. 10c), the enhanced thermal effect promoted the recombination of vacancies with interstitials, resulting in an evident decrease of vacancies, and only the defect state of slope II was shown in the S-W plot. When the energy densities were up to $1.2 \mathrm{~J} / \mathrm{cm}^{2}$ and $2.0 \mathrm{~J} / \mathrm{cm}^{2}$, a new type of defect (slope III) appeared in addition to the type of slope II . Combined with the results of HRTEM, for the CoCrFeMnNi HEA after $0.3 \mathrm{~J} / \mathrm{cm}^{2}, 300$ pulses and $2.0 \mathrm{~J} / \mathrm{cm}^{2}, 3$ pulses irradiation, $\mathrm{SFs} \mathrm{de}-$ fects were produced, and the defect type of slope II in the S-W curve of both samples should be correlated with SFs defects. Notice that the S parameter of the S-W curve for slope III did not change significantly, while the $\mathrm{W}$ parameter increased, indicating 


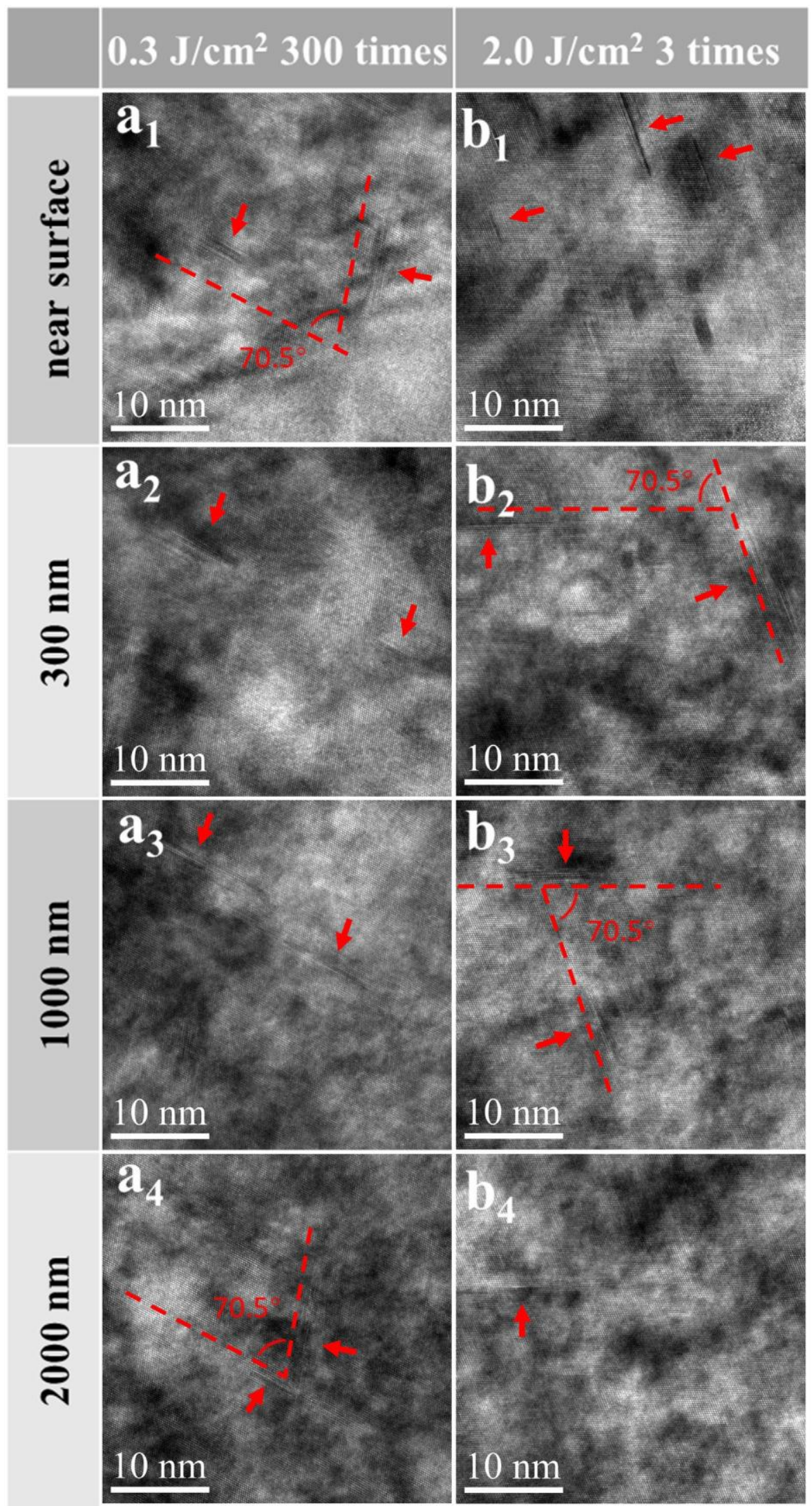

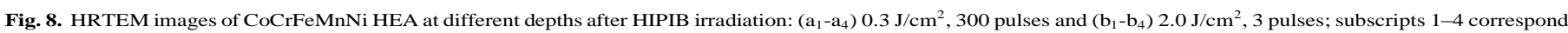
to the region of near surface, $300 \mathrm{~nm}$ depth, $1 \mu \mathrm{m}$ depth and $2 \mu \mathrm{m}$ depth, respectively; the electron beam is along [110] zone axis. 

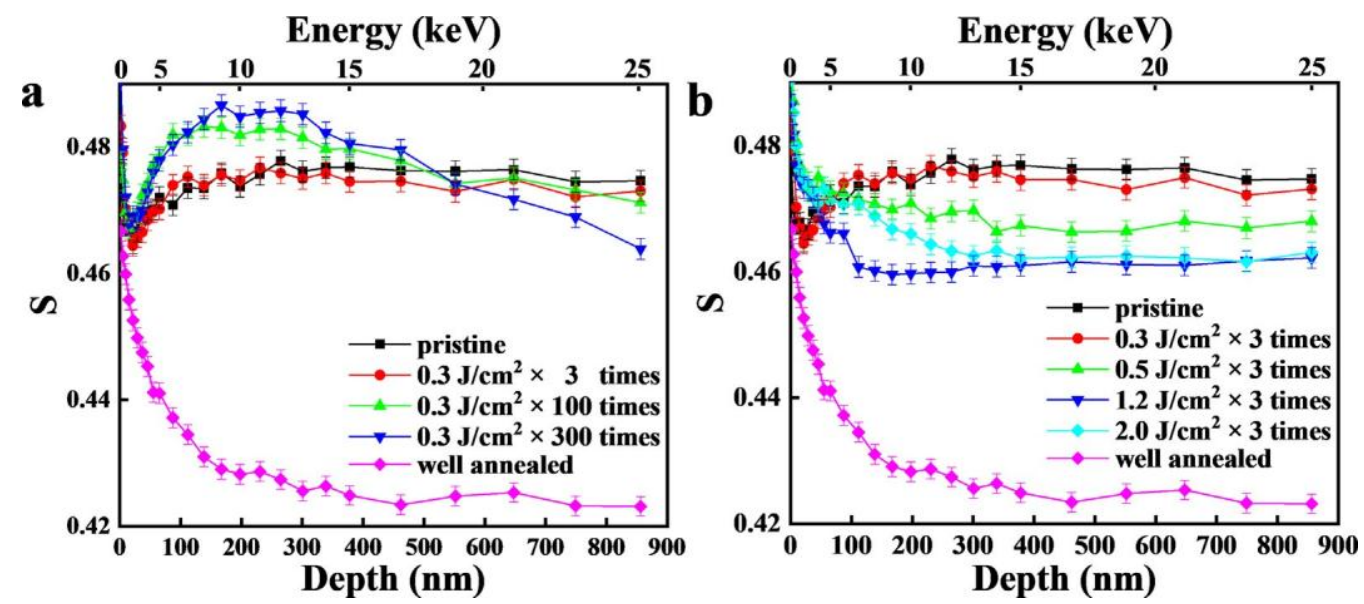

Fig. 9. S-depth curves for the CoCrFeMnNi HEA before and after HIPIB irradiation: (a) $0.3 \mathrm{~J} / \mathrm{cm}^{2}$, different pulses and (b) different energy densities, 3 pulses.
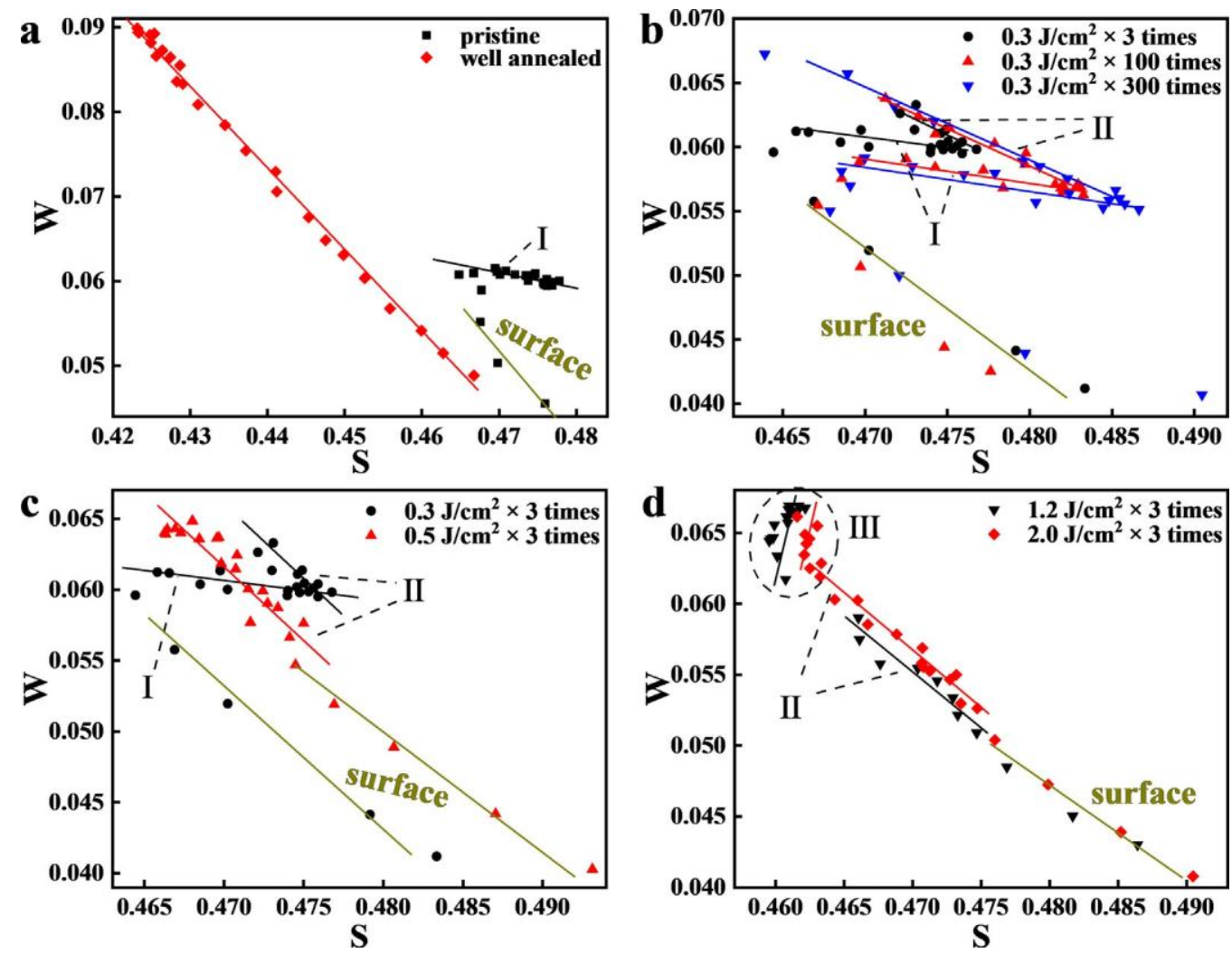

Fig. 10. S-W plots for the CoCrFeMnNi HEA before and after HIPIB irradiation: (a) pristine and well annealed, (b) $0.3 \mathrm{~J} / \mathrm{cm}^{2}$, different pulses, (c) $0.3-0.5 \mathrm{~J} / \mathrm{cm}^{2}$ and $(\mathrm{d})$ $1.2-2.0 \mathrm{~J} / \mathrm{cm}^{2}, 3$ pulses; I, II and III are different types of slopes, respectively.

a change of the elemental distribution around vacancy-type defects [58]. After $1.2 \mathrm{~J} / \mathrm{cm}^{2}$ and $2.0 \mathrm{~J} / \mathrm{cm}^{2}$ irradiation, the elements of CoCrFeMnNi HEA redistributed due to the rapid remelting and solidification, and the change of elements around the vacancies may lead to the generation of the defect of slope III type.

The surface morphology images of the CoCrFeMnNi HEA before and after HIPIB irradiation are given in Fig. 11. The surface of the un-irradiated CoCrFeMnNi HEA was smooth and flat (Fig. 11a). When the energy density was $0.3 \mathrm{~J} / \mathrm{cm}^{2}$, no significant irradiation damage was observed on the surface of CoCrFeMnNi HEA even after the pulses reached 300 times (Fig. 11c). There was no significant change after the irradiation of $0.5 \mathrm{~J} / \mathrm{cm}^{2}, 3$ pulses (Fig. 11d), either. When the energy density increased to $1.2 \mathrm{~J} / \mathrm{cm}^{2}$ (Fig. 11e) and $2.0 \mathrm{~J} / \mathrm{cm}^{2}$ (Fig. 11f), the craters formed. There are many rea- sons for the generation of craters (such as the preferential vaporization of low melting point elements $[59,60]$ or the hitting of impurities from ion source diode on the material surface [61], etc.), but there is no unified statement so far. However, the melting of material surface is a necessary condition for generating craters. By the simulation of temperature field, remelting of the surface layer occurred at $1.2 \mathrm{~J} / \mathrm{cm}^{2}$ and $2.0 \mathrm{~J} / \mathrm{cm}^{2}$, and the melting region was deeper and the melting duration was longer at $2.0 \mathrm{~J} / \mathrm{cm}^{2}$ (Table 1). With the increase of melting duration, the crater edge of the annular bulge diffused to both sides due to the effect of surface tension at the melting state [62], resulting in the larger crater size and flatter edge at $2.0 \mathrm{~J} / \mathrm{cm}^{2}$. The effect of energy density on the surface morphology of CoCrFeMnNi HEA is greater than the pulses. 


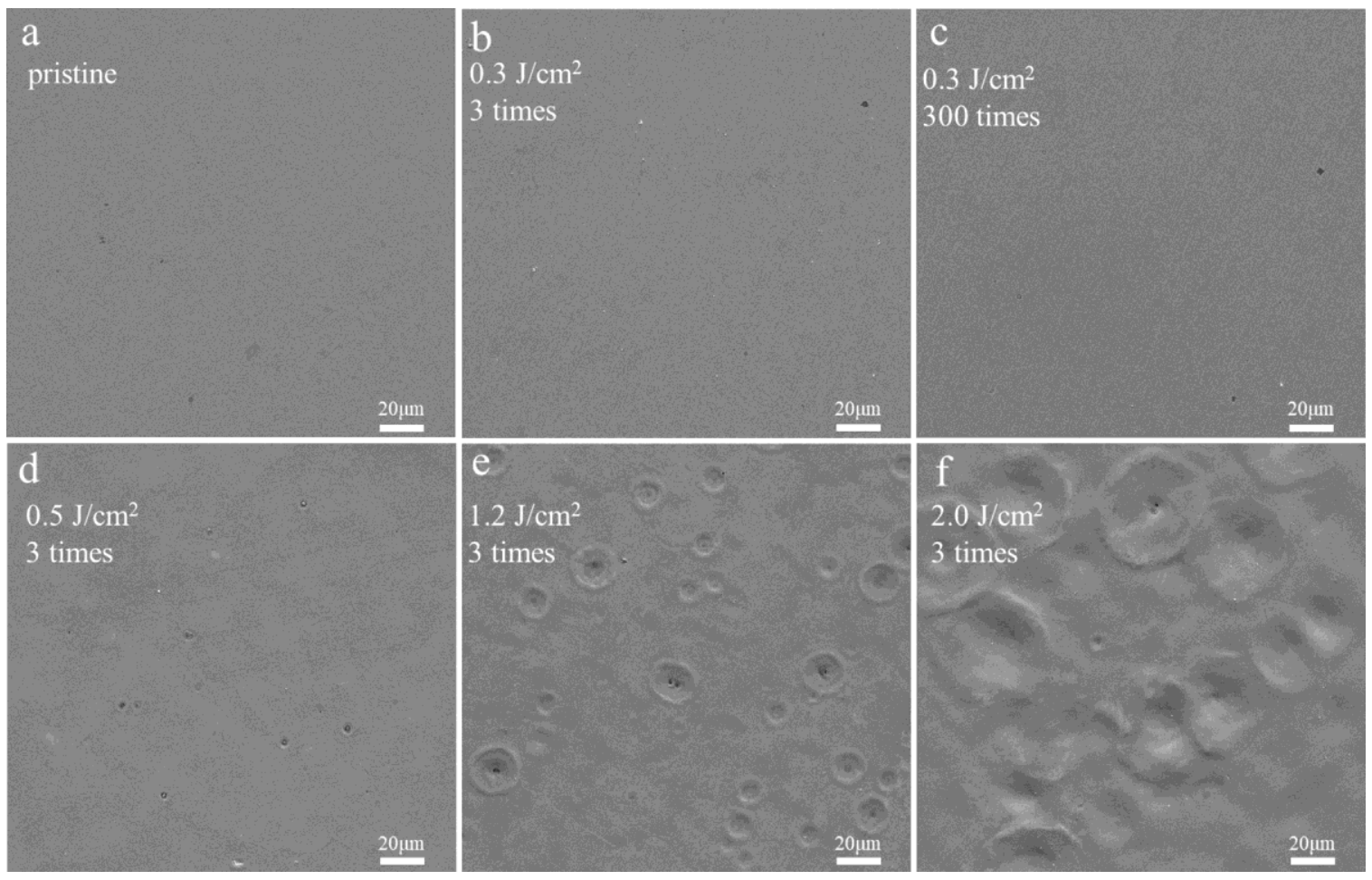

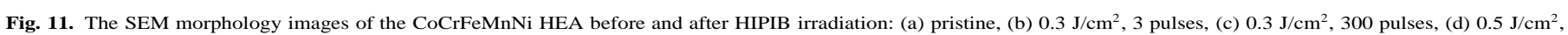
3 pulses, (e) $1.2 \mathrm{~J} / \mathrm{cm}^{2}, 3$ pulses, (f) $2.0 \mathrm{~J} / \mathrm{cm}^{2}, 3$ pulses.

In previous experiment, cracks appeared on the surface of tungsten after the HIPIB irradiation of $0.25 \mathrm{~J} / \mathrm{cm}^{2}, 100$ pulses and $1.4 \mathrm{~J} / \mathrm{cm}^{2}, 3$ pulses [49]. The surface cracks of CoCrFeMnNi HEA were not observed under the stronger irradiation conditions of $0.3 \mathrm{~J} / \mathrm{cm}^{2}, 300$ pulses or $2.0 \mathrm{~J} / \mathrm{cm}^{2}, 3$ pulses. CoCrFeMnNi HEA has a lower SFE due to its severe lattice distortion, and the high-level chemical disorder leads to variation in local lattice potential and SFE, forming a high resistance to dislocation slip [63]. As a result, the fracture toughness of CoCrFeMnNi HEA $\left(\sim 217 \mathrm{MPa}^{-\mathrm{m}^{1 / 2}}[64]\right)$ is much higher than that of the tungsten $\left(\sim 30 \mathrm{MPa}^{-\mathrm{m}^{1 / 2}}[65]\right)$, which inhibits the generation of cracks. Therefore, CoCrFeMnNi HEA has stronger resistance to HIPIB irradiation-induced crack than tungsten.

The variations of hardness with depth of CoCrFeMnNi HEA before and after HIPIB irradiation were shown by Fig. 12. The hardness near surface of CoCrFeMnNi HEA decreased after irradiation, and the difference was not identified between various irradiation conditions. The SF defects (as a pegging effect) and residual stresses produced by irradiation contributed to hardening, while the thermal effect decreased the hardness near surface by eliminating the cold-work hardening produced by the mechanical polishing of surface. The difference in hardness before and after irradiation gradually disappeared with increasing depth, and the hardness was almost the same at $2 \mu \mathrm{m}$ depth. Similar softening by eliminating the cold-work hardening was also observed in tungsten irradiated by HIPIB [49].

HIPIB irradiation produced ion beam effect, thermal effect and shock wave effect within the CoCrFeMnNi HEA, resulting in a large number of vacancies, high temperature and high stress. The three effects synergistically affected the microstructure, surface morphology and mechanical properties of CoCrFeMnNi HEA. The distributions of dpa and ions concentrations with depth (the ion beam effect), and the evolutions of temperature and thermal stress with time and space (thermal effect and shock wave effect) were simulated. Sort the three effects by influence depth, the result is:

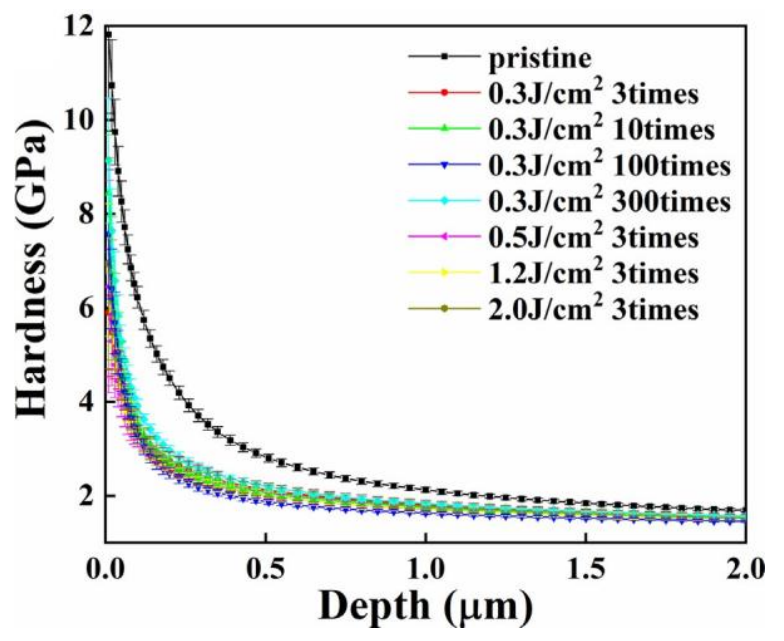

Fig. 12. The depth-dependent variations of hardness for the CoCrFeMnNi HEA before and after HIPIB irradiation.

shock wave effect $>$ thermal effect $>$ ion beam effect. The maximum temperature of $\mathrm{CoCrFeMnNi}$ HEA irradiated with the energy density of $1.2 \mathrm{~J} / \mathrm{cm}^{2}$ and $2.0 \mathrm{~J} / \mathrm{cm}^{2}$ exceeded the melting point. Remelting led to the formation of craters, while the tensile stress caused by rapid solidification increased the lattice parameter of the remelted layer slightly. The higher lattice strain energy due to the higher lattice distortion of HEA suppresses the change in lattice parameter. For the CoCrFeMnNi HEA that did not reach the melting point, the lattice parameter changes were less than those of the tungsten under similar conditional irradiation. In addition, the compressive stress produced by shock wave effect was greater than the yield strength, resulting in the compression of lattice within the CoCrFeMnNi HEA. After HIPIB irradiation, CoCrFeMnNi HEA still 
maintained the FCC single-phase structure without change and had good phase stability.

After the irradiation of $0.3 \mathrm{~J} / \mathrm{cm}^{2}, 100-300$ pulses, due to the ion beam effect, a large number of vacancies accumulated in the cascaded collision region $(0-400 \mathrm{~nm})$, resulting in an obvious defect layer. The pristine CoCrFeMnNi HEA has a high concentration of vacancies because of the high configurational entropy. After the irradiation of $0.5-2.0 \mathrm{~J} / \mathrm{cm}^{2}, 3$ pulses, the thermal effect promoted the recombination of vacancies with interstitials, thus decreased the concentration of vacancies. The severe lattice distortion makes CoCrFeMnNi HEA have a lower stacking fault energy than conventional alloys, meanwhile ion collisions, high temperature and stress all promoted the migration of vacancies to form SFs, so that the SFs generated even at the depth far beyond the ion range. After $1.2 \mathrm{~J} / \mathrm{cm}^{2}$ and $2.0 \mathrm{~J} / \mathrm{cm}^{2}$ irradiation, a new type defects generated in $\mathrm{CoCrFeMnNi}$ HEA because of the redistribution of elements by rapid remelting and solidification.

CoCrFeMnNi HEA has a lower SFE, and its high-level chemical disorder leads to variation of local lattice potential and SFE, forming a high resistance to dislocation slip, which gives much higher fracture toughness to CoCrFeMnNi HEA than tungsten. Therefore, CoCrFeMnNi HEA has stronger resistance to HIPIB irradiationinduced crack than tungsten, and no cracks were produced under similar conditions of HIPIB irradiation.

\section{Conclusion}

CoCrFeMnNi HEA with single-phase FCC structure was irradiated by HIPIB to investigate the effects of thermal shock irradiation on its microstructure, surface morphology and mechanical properties. The following conclusions were obtained:

a) After HIPIB irradiation, the rapid solidification and shock wave effect produced residual stress in the CoCrFeMnNi HEA, but the CoCrFeMnNi HEA maintained the FCC single-phase structure and had good phase stability. Due to the high lattice strain energy, the lattice parameter changes of $\mathrm{CoCrFeMnNi} \mathrm{HEA}$ were less than those of tungsten under similar conditional HIPIB irradiation.

b) The ion beam effect of irradiation produced a large number of vacancies within the CoCrFeMnNi HEA through cascade collisions after the irradiation of multiple pulses, low energy density $\left(0.3 \mathrm{~J} / \mathrm{cm}^{2}, 100-300\right.$ pulses $)$. The pristine CoCrFeMnNi HEA has numerous vacancies, and the thermal effect promoted the recombination of vacancies with interstitials, reducing the concentration of vacancies after the irradiation of high energy density, few pulses $\left(0.5-2.0 \mathrm{~J} / \mathrm{cm}^{2}, 3\right.$ pulses $)$. In addition, the generation of SFs was observed after all irradiation conditions, and a new type defects generated because of the redistribution of elements by rapid remelting and solidification after $1.2 \mathrm{~J} / \mathrm{cm}^{2}$ and $2.0 \mathrm{~J} / \mathrm{cm}^{2}$ irradiation.

c) The surface layer of CoCrFeMnNi HEA remelted and produced craters after the irradiation of $1.2 \mathrm{~J} / \mathrm{cm}^{2}$ and $2.0 \mathrm{~J} / \mathrm{cm}^{2}$. Due to the large compositional complexity and the high-level chemical disorder, CoCrFeMnNi HEA exhibited better irradiation-induced cracks resistance than the tungsten after similar conditional HIPIB irradiation.

\section{Declaration of Competing Interest}

The work described has not been published before; it is not under consideration for publication anywhere else; and publication has been approved by all co-authors and the responsible authorities at the institute where the work has been carried out.

\section{CRediT authorship contribution statement}

Lisong Zhang: Writing - original draft, Software. Xiaonan Zhang: Investigation. Na Li: Investigation. Xianxiu Mei: Conceptualization, Methodology, Funding acquisition, Project administration. Xiaona Li: Methodology. Younian Wang: Supervision. Xingzhong Cao: Resources, Writing - review \& editing. Sergey K. Pavlov: Resources, Writing - review \& editing. Vladimir V. Uglov: Resources, Writing - review \& editing. Eryang Lu: Resources.

\section{Acknowledgement}

This work was supported by the National Natural Science Foundation of China (No. 11975065 and No. 11911530086).

\section{References}

[1] P. Yvon, F. Carré, Structural materials challenges for advanced reactor systems, J. Nucl. Mater. 385 (2009) 217-222, doi:10.1016/j.jnucmat.2008.11.026.

[2] P. Hosemann, D. Frazer, M. Fratoni, A. Bolind, M.F. Ashby, Materials selection for nuclear applications: challenges and opportunities, Scr. Mater. 143 (2018) 181187, doi:10.1016/j.scriptamat.2017.04.027.

[3] J.-.W. Yeh, S.-.K. Chen, S.-.J. Lin, J.-.Y. Gan, T.-.S. Chin, T.-.T. Shun, C.-.H. Tsau, S.-.Y. Chang, Nanostructured high-entropy alloys with multiple principal elements: novel alloy design concepts and outcomes, Adv. Eng. Mater. 6 (2004) 299303, doi:10.1002/adem.200300567.

[4] Y. Zhang, T.T. Zuo, Z. Tang, M.C. Gao, K.A. Dahmen, P.K. Liaw, Z.P. Lu, Microstructures and properties of high-entropy alloys, Prog. Mater. Sci. 61 (2014) 193, doi:10.1016/j.pmatsci.2013.10.001.

[5] Z. Li, S. Zhao, R.O. Ritchie, M.A. Meyers, Mechanical properties of high-entropy alloys with emphasis on face-centered cubic alloys, Prog. Mater. Sci. 102 (2019) 296-345, doi:10.1016/j.pmatsci.2018.12.003.

[6] S. Praveen, H.S. Kim, High-entropy alloys: potential candidates for hightemperature applications - an overview, Adv. Eng. Mater. 20 (2018) 1700645, doi:10.1002/adem.201700645.

[7] Z. Wu, H. Bei, G.M. Pharr, E.P. George, Temperature dependence of the mechanical properties of equiatomic solid solution alloys with face-centered cubic crystal structures, Acta Mater. 81 (2014) 428-441, doi:10.1016/j.actamat.2014. 08.026.

[8] E.J. Pickering, A.W. Carruthers, P.J. Barron, S.C. Middleburgh, D.E.J. Armstrong, A.S. Gandy, High-entropy alloys for advanced nuclear applications, Entropy 23 (2021) 1-28, doi:10.3390/e23010098.

[9] Y. Zhang, G.M. Stocks, K. Jin, C. Lu, H. Bei, B.C. Sales, L. Wang, L.K. Béland, R.E. Stoller, G.D. Samolyuk, M. Caro, A. Caro, W.J. Weber, Influence of chemical disorder on energy dissipation and defect evolution in concentrated solid solution alloys, Nat. Commun. 6 (2015), doi:10.1038/ncomms9736.

[10] B. Cantor, I.T.H. Chang, P. Knight, A.J.B. Vincent, Microstructural development in equiatomic multicomponent alloys, Mater. Sci. Eng. A. 375-377 (2004) 213218, doi:10.1016/j.msea.2003.10.257.

[11] K. Jin, C. Lu, L.M. Wang, J. Qu, W.J. Weber, Y. Zhang, H. Bei, Effects of compositional complexity on the ion-irradiation induced swelling and hardening in Ni-containing equiatomic alloys, Scr. Mater. 119 (2016) 65-70, doi:10.1016/j. scriptamat 2016.03.030.

[12] C. Lu, L. Niu, N. Chen, K. Jin, T. Yang, P. Xiu, Y. Zhang, F. Gao, H. Bei, S. Shi, M..R. He, I.M. Robertson, W.J. Weber, L. Wang, Enhancing radiation tolerance by controlling defect mobility and migration pathways in multicomponent singlephase alloys, Nat. Commun. 7 (2016) 13564, doi:10.1038/ncomms13564.

[13] C. Lu, T. Yang, K. Jin, N. Gao, P. Xiu, Y. Zhang, F. Gao, H. Bei, W.J. Weber, K. Sun, Y. Dong, L. Wang, Radiation-induced segregation on defect clusters in single-phase concentrated solid-solution alloys, Acta Mater. 127 (2017) 98-107, doi:10.1016/j.actamat.2017.01.019.

[14] H.-.S. Do, B.-.J. Lee, Origin of radiation resistance in multi-principal element alloys, Sci. Rep. 8 (2018) 16015, doi:10.1038/s41598-018-34486-5.

[15] L. Yang, H. Ge, J. Zhang, T. Xiong, Q. Jin, Y. Zhou, X. Shao, B. Zhang, Z. Zhu, S. Zheng, X. Ma, High He-ion irradiation resistance of CrMnFeCoNi highentropy alloy revealed by comparison study with $\mathrm{Ni}$ and 304SS, J. Mater. Sci. Technol. 35 (2019) 300-305, doi:10.1016/j.jmst.2018.09.050.

[16] S.J. Zinkle, G.S. Was, Materials challenges in nuclear energy, Acta Mater 61 (2013) 735-758, doi:10.1016/j.actamat.2012.11.004.

[17] N.A.P.K. Kumar, C. Li, K.J. Leonard, H. Bei, S.J. Zinkle, Microstructural stability and mechanical behavior of $\mathrm{FeNiMnCr}$ high entropy alloy under ion irradiation, Acta Mater 113 (2016) 230-244, doi:10.1016/j.actamat.2016.05.007.

[18] T. Nagase, P.D. Rack, J.H. Noh, T. Egami, In-situ TEM observation of structural changes in nano-crystalline $\mathrm{CoCrCuFeNi}$ multicomponent high-entropy alloy (HEA) under fast electron irradiation by high voltage electron microscopy (HVEM), Intermetallics 59 (2015) 32-42, doi:10.1016/j.intermet.2014.12.007.

[19] T. Yang, C. Lu, G. Velisa, K. Jin, P. Xiu, Y. Zhang, H. Bei, L. Wang, Influence of irradiation temperature on void swelling in NiCoFeCrMn and NiCoFeCrPd, Scr. Mater. 158 (2019) 57-61, doi:10.1016/j.scriptamat.2018.08.021.

[20] D. Chen, S. Zhao, J. Sun, P. Tai, Y. Sheng, Y. Zhao, G. Yeli, W. Lin, S. Liu, W. Kai, J.-.J. Kai, Diffusion controlled helium bubble formation resistance of $\mathrm{FeCoNiCr}$ 
high-entropy alloy in the half-melting temperature regime, J. Nucl. Mater. 526 (2019) 151747, doi:10.1016/j.jnucmat.2019.151747

[21] D. Chen, Y. Tong, H. Li, J. Wang, Y.L. Zhao, A. Hu, J.J. Kai, Helium accumulation and bubble formation in $\mathrm{FeCoNiCr}$ alloy under high fluence $\mathrm{He}+$ implantation, J. Nucl. Mater. 501 (2018) 208-216, doi:10.1016/j.jnucmat.2018.01.041.

[22] A. Suslova, O. El-Atwani, S.S. Harilal, A. Hassanein, Material ejection and surface morphology changes during transient heat loading of tungsten as plasmafacing component in fusion devices, Nucl. Fusion. 55 (2015) 033007, doi: 10. 1088/0029-5515/55/3/033007.

[23] G.E. Remnev, V.A. Shulov, Application of high-power ion beams for technology, Laser Part. Beams. 11 (1993) 707-731, doi:10.1017/S0263034600006467.

[24] A... Pogrebnjak, V... Shablya, N... Sviridenko, A... Valyaev, S... Plotnikov, M... Kylyshkanov, Study of deformation states in metals exposed to intensepulsed-ion beams (IPIB), Surf. Coatings Technol.. 111 (1999) 46-50. https://doi.org/10.1016/S0257-8972(98)00702-6.

[25] A.D. Pogrebnjak, G.E. Remnev, I.E. Kurakin, A.E. Ligachev, Structural, physical and chemical changes induced in metals and alloys exposed to high power ion beams, Nucl. Instruments Methods Phys. Res. Sect. B Beam Interact. Mater. Atoms. 36 (1989) 286-305, doi:10.1016/0168-583X(89)90671-X.

[26] A.D. Pogrebnjak, A.E. Ligachev, A.V. Nesmelov, V.P. Nesterenko, L.N. Puchkareva, V.N. Pirogov, G.E. Remnev, I.F. Isakov, S.M. Ruzimov, Structure modifications and mechanical properties of alloys exposed to pulsed ion beams, Radiat. Eff. 102 (1987) 103-115, doi:10.1080/00337578708222910.

[27] X. Liu, X. Mei, J. Qiang, G.E.E. Remnev, Y. Wang, Effects on structure and properties of Zr55Al10Cu30Ni5 metallic glass irradiated by high intensity pulsed ion beam, Appl. Surf. Sci. 313 (2014) 911-917, doi:10.1016/j.apsusc.2014.06.106.

[28] J. Shen, I. Shahid, X. Yu, J. Zhang, H. Zhong, X. Cui, G. Liang, X. Yu, W. Huang, S. Yan, G. Zhang, X. Zhang, X. Le, Fracture analysis of surface exfoliation on single crystal silicon irradiated by intense pulsed ion beam, Nucl. Instruments Methods Phys. Res. Sect. B Beam Interact. with Mater. Atoms. 413 (2017) 6-12, doi:10.1016/j.nimb.2017.09.031

[29] X. Le, S. Yan, Z. Liu, W. Zhao, Detection of shocks generated by intense pulsed ion beam irradiation, Surf. Coatings Technol. 201 (2007) 4991-4994, doi:10. 1016/j.surfcoat.2006.07.201.

[30] J.Alvarez Ruiz, A. Rivera, K. Mima, D. Garoz, R. Gonzalez-Arrabal, N. Gordillo, J. Fuchs, K. Tanaka, I. Fernández, F. Briones, J. Perlado, Plasma-wall interaction in laser inertial fusion reactors: novel proposals for radiation tests of first wall materials, Plasma Phys. Control. Fusion. 54 (2012) 124051, doi:10.1088/ 0741-3335/54/12/124051.

[31] T. Guan, X. Zhang, L. Zhang, N. Li, X. Li, Y. Wang, X. Mei, G.E. Remnev, S.K. Pavlov, V.V. Uglov, Study on the damage of Fe80B13Si7 alloy with different structure by high-intensity pulsed ion beam irradiation, Surf. Coatings Technol. 395 (2020) 125933, doi:10.1016/j.surfcoat.2020.125933.

[32] Y. Dong, Y. Lu, J. Kong, J. Zhang, T. Li, Microstructure and mechanical properties of multi-component AlCrFeNiMo x high-entropy alloys, J. Alloys Compd. 573 (2013) 96-101, doi:10.1016/j.jallcom.2013.03.253.

[33] Y. Dong, K. Zhou, Y. Lu, X. Gao, T. Wang, T. Li, Effect of vanadium addition on the microstructure and properties of AlCoCrFeNi high entropy alloy, Mater. Des. 57 (2014) 67-72, doi:10.1016/j.matdes.2013.12.048.

[34] G.E. Remnev, I.F. Isakov, M.S. Opekounov, V.M. Matvienko, V.A. Ryzhkov, V.K. Struts, I.I. Grushin, A.N. Zakoutayev, A.V. Potyomkin, V.A. Tarbokov, A.N. Pushkaryov, V.L. Kutuzov, M.Y. Ovsyannikov, High intensity pulsed ion beam sources and their industrial applications, Surf. Coatings Technol. 114 (1999) 206-212, doi:10.1016/S0257-8972(99)00058-4.

[35] G.E. Remnev, I.F. Isakov, M.S. Opekounov, G.I. Kotlyarevsky, V.L. Kutuzov, V.S. Lopatin, V.M. Matvienko, M.Y. Ovsyannikov, A.V. Potyomkin, V.A. Tarbokov, High-power ion beam sources for industrial application, Surf. Coatings Technol. 96 (1997) 103-109, doi:10.1016/S0257-8972(97)00116-3.

[36] J.F. Ziegler, J.P. Biersack, The stopping and range of ions in matter, in: Treatise Heavy-Ion Sci, Springer US, Boston, MA, 1985, pp. 93-129, doi:10.1007/ 978-1-4615-8103-1_3

[37] X. Yu, J. Shen, M. Qu, H. Zhong, J. Zhang, Y. Zhang, S. Yan, G. Zhang, X. Zhang, $\mathrm{X}$. Le, Distribution and evolution of thermal field formed by intense pulsed ion beam on thin metal target, Nucl. Instruments Methods Phys. Res. Sect. B Beam Interact. with Mater. Atoms. 365 (2015) 225-229, doi:10.1016/j.nimb.2015.07. 061.

[38] W. Ping, M. Yan-Yun, Q. Xiu-Bo, Z. Zhe, C. Xing-Zhong, Y. Run-Sheng, W. Bao-Yi, Performance of the plugged-in $22 \mathrm{Na}$ based slow positron beam facility, Chinese Phys. C. 32 (2008) 243-246. https://doi.org/10.1088/1674-1137/32/3/017.

[39] W.J. Weber, Y. Zhang, Predicting damage production in monoatomic and multielemental targets using stopping and range of ions in matter code: challenges and recommendations, Curr. Opin. Solid State Mater. Sci. 23 (2019) 100757, doi:10.1016/j.cossms.2019.06.001.

[40] C.M. Barr, J.E. Nathaniel, K.A. Unocic, J. Liu, Y. Zhang, Y. Wang, M.L. Taheri, Exploring radiation induced segregation mechanisms at grain boundaries in equiatomic CoCrFeNiMn high entropy alloy under heavy ion irradiation, Scr. Mater. 156 (2018) 80-84, doi:10.1016/j.scriptamat.2018.06.041.

[41] Y. Tong, G. Velisa, S. Zhao, W. Guo, T. Yang, K. Jin, C. Lu, H. Bei, J.Y.P. Ko, D.C. Pagan, Y. Zhang, L. Wang, F.X. Zhang, Evolution of local lattice distortion under irradiation in medium- and high-entropy alloys, Materialia 2 (2018) 73-81, doi:10.1016/j.mtla.2018.06.008

[42] M. Vaidya, K.G. Pradeep, B.S. Murty, G. Wilde, S.V. Divinski, Bulk tracer diffusion in $\mathrm{CoCrFeNi}$ and $\mathrm{CoCrFeMnNi}$ high entropy alloys, Acta Mater 146 (2018) 211-224, doi:10.1016/j.actamat.2017.12.052
[43] Q. Zhang, X. Mei, T. Guan, X. Zhang, G.E. Remnev, S.K. Pavlov, Y. Wang, Effects of high-intensity pulsed ion beam irradiation on the structural thermal stability of Fe80Si7.43B12.57 metallic glass, Fusion Eng. Des. 138 (2019) 16-23, doi:10.1016/j.fusengdes.2018.10.012.

[44] G. Laplanche, P. Gadaud, O. Horst, F. Otto, G. Eggeler, E.P. George, Temperature dependencies of the elastic moduli and thermal expansion coefficient of an equiatomic, single-phase $\mathrm{CoCrFeMnNi}$ high-entropy alloy, J. Alloys Compd. 623 (2015) 348-353, doi:10.1016/j.jallcom.2014.11.061

[45] K. Jin, S. Mu, K. An, W.D. Porter, G.D. Samolyuk, G.M. Stocks, H. Bei, Thermophysical properties of Ni-containing single-phase concentrated solid solution alloys, Mater. Des. 117 (2017) 185-192, doi:10.1016/j.matdes.2016.12.079.

[46] Z. Wu, H. Bei, F. Otto, G.M. Pharr, E.P. George, Recovery, recrystallization, grain growth and phase stability of a family of FCC-structured multi-component equiatomic solid solution alloys, Intermetallics 46 (2014) 131-140, doi:10.1016/ j.intermet.2013.10.024.

[47] F. Otto, A. Dlouhý, C. Somsen, H. Bei, G. Eggeler, E.P.P. George, The influences of temperature and microstructure on the tensile properties of a CoCrFeMnNi highentropy alloy, Acta Mater 61 (2013) 5743-5755, doi:10.1016/j.actamat. 2013.06.018.

[48] A. Gali, E.P. George, Tensile properties of high- and medium-entropy alloys, Intermetallics 39 (2013) 74-78, doi:10.1016/j.intermet.2013.03.018.

[49] X. Mei, X. Zhang, X. Liu, Y. Wang, Effect on structure and mechanical property of tungsten irradiated by high intensity pulsed ion beam, Nucl. Instruments Methods Phys. Res. Sect. B Beam Interact. Mater. Atoms. 406 (2017) 697-702, doi:10.1016/j.nimb.2017.03.117.

[50] R.S. Mishra, N. Kumar, M. Komarasamy, Lattice strain framework for plastic deformation in complex concentrated alloys including high entropy alloys, Mater. Sci. Technol. (United Kingdom). 31 (2015) 1259-1263, doi:10.1179/ 1743284715 Y.0000000050.

[51] A.J. Zaddach, C. Niu, C.C. Koch, D.L. Irving, Mechanical properties and stacking fault energies of NiFeCrCoMn high-entropy alloy, JOM 65 (2013) 1780-1789, doi:10.1007/s11837-013-0771-4.

[52] R. Sachan, M.W. Ullah, M.F. Chisholm, J. Liu, P. Zhai, D. Schauries, P. Kluth, C. Trautman, H. Bei, W.J. Weber, Y. Zhang, Radiation-induced extreme elastic and inelastic interactions in concentrated solid solutions, Mater. Des. 150 (2018) 1-8, doi:10.1016/j.matdes.2018.04.011

[53] S. Abhaya, R. Rajaraman, S. Kalavathi, C. David, B.K. Panigrahi, G. Amarendra, Effect of dose and post irradiation annealing in $\mathrm{Ni}$ implanted high entropy alloy $\mathrm{FeCrCoNi}$ using slow positron beam, J. Alloys Compd. 669 (2016) 117-122, doi:10.1016/j.jallcom.2016.01.242.

[54] C. Li, X. Cao, X. Ning, F. Liu, B. Wang, P. Zhang, L. Wei, D. Li, Implantation profiles and depth distribution of slow positron beam simulated by Geant 4 toolkit, Phys. Scr. (2019) 94, doi:10.1088/1402-4896/aafaa2.

[55] Z. Wang, C.T. Liu, P. Dou, Thermodynamics of vacancies and clusters in high-entropy alloys, Phys. Rev. Mater. 1 (2017) 043601, doi:10.1103/ PhysRevMaterials.1.043601.

[56] Y. Lu, H. Huang, X. Gao, C. Ren, J. Gao, H. Zhang, S. Zheng, Q. Jin, Y. Zhao, C. Lu, T. Wang, T. Li, A promising new class of irradiation tolerant materials: ti2ZrHfV0.5Mo0.2 high-entropy alloy, J. Mater. Sci. Technol. 35 (2019) 369-373, doi:10.1016/j.jmst.2018.09.034

[57] C. Li, X. Hu, T. Yang, N.K. Kumar, B.D. Wirth, S.J. Zinkle, Neutron irradiation response of a Co-free high entropy alloy, J. Nucl. Mater. 527 (2019) 151838, doi:10.1016/j.jnucmat.2019.151838.

[58] S. Jin, X. Lian, T. Zhu, Y. Gong, P. Zhang, X. Cao, R. Yu, B. Wang, Irradiation evolution of $\mathrm{Cu}$ precipitates in $\mathrm{Fe} 1.0 \mathrm{Cu}$ alloy studied by positron annihilation spectroscopy, J. Nucl. Mater. 499 (2018) 65-70, doi:10.1016/j.jnucmat.2017.11. 011.

[59] V.S. Kovivchak, T.V. Panova, K.A. Mikhailov, E.V. Knyazev, Features of the surface morphology of brass and bronze upon irradiation with a high power ion beam, J. Surf. Investig. 7 (2013) 531-535, doi:10.1134/S1027451013020365.

[60] D.J. Rej, H.A. Davis, M. Nastasi, J.C. Olson, E.J. Peterson, R.D. Reiswig, K.C. Walter, R.W. Stinnett, G.E. Remnev, V.K. Struts, Surface modification of AISI-4620 steel with intense pulsed ion beams, Nucl. Instruments Methods Phys. Res. Sect. B Beam Interact. with Mater. Atoms. 127-128 (1997) 987-991, doi:10. 1016/S0168-583X(97)00044-X

[61] S. Yan, X.Y. Le, W.J. Zhao, J.M. Xue, Y.G. Wang, A possible thermodynamic mechanism of craters formation on metal surfaces caused by intense pulsed ion beams, Surf. Coatings Technol. 193 (2005) 69-74, doi:10.1016/j.surfcoat. 2004.07.063.

[62] X. Yu, J. Shen, H. Zhong, J. Zhang, S. Yan, G. Zhang, X. Zhang, X. Le, Thermohydrodynamic process simulation of craters formation and evolution on metal surfaces caused by intense pulsed ion beams, Vacuum 120 (2015) 116-120, doi:10.1016/j.vacuum.2015.06.028.

[63] Z. Zhang, M.M. Mao, J. Wang, B. Gludovatz, Z. Zhang, S.X. Mao, E.P. George, Q. Yu, R.O. Ritchie, Nanoscale origins of the damage tolerance of the highentropy alloy CrMnFeCoNi, Nat. Commun. 6 (2015) 10143, doi:10.1038/ ncomms10143.

[64] B. Gludovatz, A. Hohenwarter, D. Catoor, E.H. Chang, E.P. George, R.O. Ritchie, A fracture-resistant high-entropy alloy for cryogenic applications, Science (80-.) 345 (2014) 1153-1158, doi:10.1126/science.1254581

[65] B.S. Kong, J.H. Shin, C. Jang, H.C. Kim, Measurement of fracture toughness of pure tungsten using a small-sized compact tension specimen, Materials (Basel) 13 (2020) 244, doi:10.3390/ma13010244. 